\title{
의사국가고시에서 실기시험
}

\author{
한양대학교 의과대학 가정의학교실 \\ 박 훈 기 \\ Clinical Skills Assessment in Korean Medical Licensing Examination
}

\author{
Hoonki Park
}

Department of Family Medicine, Medical Education, Hanyang University College of Medicine, Seoul, Korea

In addition to the traditional MCQ test, National Medical Licensing Examination Board (NMLEB) will introduce clinical skills assessment as an independent exam for MD qualification in 2009. The clinical skills test will evaluate six procedural skills and six clinical problems by using OSCE and CPX. The validity and reliability of the test should be established by continuing effort from experts and efficient administration. The test may change the curriculum of clinical education in many medical schools. National Health Personnel Licensing Examination Board (NHPLEB) is required to prepare this exam step by step and maintain the quality of the skills exam. There should be opportunity for medical students to participate in clinical practice during bedside teaching. Collaboration between exam institution and medical schools will be needed for a successful launching of the skills test.

한국 의과대학 · 의전원의 일반적인 교육 목표에 는 일차 의료를 수행할 수 있는 의사를 만드는 것이 들어간다. 일차의료를 수행하는 의사의 기본 임무는 기본 의학 지식을 갖추고 일차의료에서 흔한 문제 를 중심으로 환자를 진료하는 것이다. 이러한 교육 과정을 이수하고 의사의 자격을 얻으려면 지식, 태 도, 술기의 세 영역에서 균형 있는 임상 능력을 갖 추어야 한다. 의사 실기시험은 기존의 지식과 문제 해결 능력을 평가하는 전통적인 필기 자격시험과는 차별적으로 실제로 환자를 대상으로 진료를 수행할 수 있는 능력을 평가할 수 있어야 한다. 하지만 실 제 환자를 대상으로 많은 수의 수험생을 공정하게

Received: November 21, 2008

Accepted: November 25, 2008

Corresponding Author: Hoonki Park hoonkp@ hanyang.ac.kr
평가하기는 힘들다. 따라서 표준화 환자 혹은 모형, 사람을 대상으로 진료와 수기능력을 평가하는 것이 현실적으로 가능한 대안이다. 의사국가고사에서는 2009학년도 4학년이 졸업하는 시점에서 의사실기시 험을 처음으로 시행할 예정이라고 한다. 이 실기시 험은 수기 중심의 문항이 6개, 진료 수행능력을 보 는 문항이 6 개가 출제될 예정이다. 평가의 영역은 술기 능력, 병력 청취 및 신체진찰, 환자교육 능력, 커뮤니케이션 능력 등이다.

\section{1. 의사 실기시험 도입의 의의}

한국의과대학학장협의회에서 21 세기 한국의학교 육계획으로 제시한 의과대학 - 의전원의 교육목표는 기본 의학 지식과 수기 습득, 의료 현장에서의 문제 해결 능력 배양, 질병예방과 건강증진을 포함하는 전인적 치료자 양성과 의사로서의 태도를 강조 하 
고 있다. 한국 의사국가고시는 그 동안 지필고사 위 주로 운영되어 기본 지식과 문제해결 능력을 평가 하는 데는 어느 정도 발전을 보여 왔지만 평가의 영 역 중 태도와 수기 영역은 제대로 평가할 수 없는 한계점을 지니고 있었다. 이러한 배경에서 의사국가 고시의 실기 시험 도입은 우선 평가영역의 균형을 추구한다는 점에서 큰 의의를 지니고 있다. 두 번째 의사실기시험의 도입 의의는 임상실습교육이 체험 학습으로 바뀔 수 있는 좋은 기회가 된다는 점이다. 평가가 교육을 바꿀 수 있다는 교육학적인 금언에 따르면 실기시험의 도입은 의과대학 학생이나 교수 에게 학생 임상 교육을 환자 중심으로 재편할 수 있 는 좋은 계기가 될 것이다. 특히, 학생들이 환자를 옆에 두고 자기가 달성해야 할 학습목표가 환자와 대화하고 보살피고 치료해야 한다는 점에 더욱 관 심을 보이게 될 것으로 기대된다. 세 번째로는 실기 시험의 도입은 의사의 질을 향상시킬 수 있는 전기 를 마련한다는 점이다. 기존의 지필 고사로는 술기 와 태도의 최소 요구 조건을 평가할 수 없을 뿐 아 니라 윤리적인 측면이나 전문가적인 태도는 확인을 할 수 없다. 기존의 필기시험은 의과 대학을 졸업하 고 독립 진료를 할 수 있는 의사자격을 얻는 데 있 어서 실제 환자에게 중대한 해를 끼치거나 환자와 효율적으로 의사소통을 할 수 없는 질이 떨어지는 의사를 거르지 못하고 바로 내보낼 수 있는 위험성 이 있었다. 하지만 실기시험의 도입은 환자를 치료 하고 돌보는 의사의 최소 자격 기준을, 실제 환자는 아니지만 실험적인 상황에서 기본 진료를 시행할 수 있는 능력을 보유하고 있는가에 두기 때문에 의 사의 질 향상을 꾀할 수 있다는 논리이다. 물론 탈 락자에 대해서는 재교육이 전제 되어야 한다. 마지 막으로 미국이나 캐나다, 영연방 국가 등의 다른 선 진국의 예를 볼 때, 실기시험은 의료시장 개방에 따 라 해외로부터 유입되는 의료자원 관리에 내실을 기할 수 있다. 이는 외국의대를 졸업하고 자국에 진 입하려는 의사들이 단순한 지적 기능뿐 아니라 진 료나 의료대화능력을 갖추고 있는지를 동시에 평가 할 수 있기 때문이다.

\section{2. 현재까지 알려진 의사실기시험의 운영 방향}

미국 ECFMG (Educational Commission for Foreign Medical Graduates)에서는 1998년 외국 의과대학 졸 업자를 대상으로 의사 실기시험 (Clinical Skills Assessment)을 도입하였다. ECFMG는 수년간의 의 사실기시험 경험을 토대로 2004년부터 NBME (National Board of Medical Examiners)와 공동으로 CSEC (Clinical Skills Evaluation Collaboration)을 구 성하여 미국 의대와 외국 의대 졸업자를 대상으로 전국 5 개 시험 센터에서 연중 USMLE (United States Medical Licensing Examination) 2단계 CS (Clinical Skills)를 시행하고 있다. 이보다 앞서 캐나다는 1992 년부터 의대 졸업 후 임상 경험 1 년을 한 후에 MCCQE (Medical Council of Canada Qualifying Examination) 제 2부 실기시험을 합격해야 의사자격 을 얻을 수 있도록 하였다. 이 두 나라의 실기시험 도입 전까지의 준비 기간은 적어도 3 5년은 된다. 이 동안 준비 팀이 한 일은 시험의 현실 적용 가능 성도 있었지만 더 중요한 것은 합격/불합격을 결정 하는 실기시험의 타당도와 신뢰도에 대한 면밀한 검토였다. 우리나라의 경우 보건의료인국가시험원 (이하 국시원)에 의사 실기시험 추진을 위한 전담반 이 2004년 11월에 결성되어 구체적인 추진안이 수 립되었으며, 2006년 6월 보건복지부에서 의사실기 시험을 2010년부터 도입한다고 공표하였다. 한편, 국시원에는 2007년 3월부터 의사실기시험전담팀이 구성되어 구체적인 시험 준비를 진행하고 있다고 알려져 있다. 시험의 운영 방법을 점검하기 위한 모 의시험이 2007년 10월과 2008년 10월 두 차례 시행 되었고 2009년 초에 최종 모의시험을 시행할 예정 으로 되어 있다. 이제까지의 국시원에서의 의사실기 시험의 준비 과정을 보면 큰 문제는 없어 보이나 앞 으로 남은 몇 달 동안의 준비 일정은 할 일에 비하 여 시간적으로 여유가 있는 것은 아니다.

현재까지 국시원에서 발표한 시험 운영 방식에서 중요한 몇 가지 사항을 정리해 보면 아래와 같다. 객관구조화진료시험 (Objective Structured Clinical Examination, OSCE) 문항 6개는 모형 혹은 사람을 
이용한 수기 혹은 신체 진찰 과정을 평가하며, 임상 진료시험 (Clinical Performance Examination, CPX) 문항 6개는 표준화 환자를 활용한 진료시험이다. $\mathrm{CPX}$ 문항은 임상적 상황을 숙지하는 시간 1 분, 환 자면담 10 분, 사이시험 (interstation) 5 분으로 구성되 며, OSCE 문항별 시간 배정은 상황 숙지 1 분, 수기 5 분이다. 중간 휴식 시간 10 분을 포함하면 한 수험 생에게 배정된 시험 시간은 대략 2 시간 40 분 가량 이다. 사이시험 스테이션에서는 각 $\mathrm{CPX}$ 문항별로 직 전의 환자 면담을 통해 얻은 정보를 종합하여 진단 가설과 향후계획을 작성해야 한다. 국시원에서는 $\mathrm{OSCE}$ 와 $\mathrm{CPX}$ 의 후보 문항 명칭을 53개, 63개씩 1 차 공지하였고, 2009년에 한하여 OSCE 40개와 $\mathrm{CPX}$ 는 56개로 축소 운영한다는 방침을 고지하였다. 아울러 국시원에서는 $\mathrm{OSCE}$ 와 관련하여 시험에서 사용될 수 있는 장비를 복수 추천하여 공지한 바 있 다. 매일 국시원의 두 고사장에서 3 부로 시험이 진 행되어 하루에 총 72 명의 수험생이 시험을 볼 수 있 다고 하며, 2009년 9월말 혹은 10월 초부터 약 2개 월 반에 걸쳐 시행될 예정이고 적어도 2009년 12 월 첫째 주까지는 완료될 예정이라고 한다. 합격 선의 결정은 수정 Angoff방법을 활용할 예정이며, 시험 문항의 합격률과 전체 총량 평균 기준 합격점 을 모두 통과해야 실기시험에 합격한 것으로 최종 결정된다고 한다. Modified Angoff 방법의 합격선 결정 방법은 전문가 $10 \sim 15$ 명이 시험 문항 각각의 내용과 채점 기준, 수험생의 시험 수행 결과 자료를 검토하여 각 시험 문항의 합격점을 결정한다. 각 문 항의 난이도에 따라 합격점은 서로 달라진다. 합격 자 발표는 2010년 1월 필기시험의 합격자 발표와 동시에 이루어진다고 한다. 필기와 실기의 합격은 다음해까지 유효하며, 어느 하나만 합격한 경우 떨 어진 시험만 다음해에 합격하면 된다. 채점 방식은 표준화 환자 활용 문항의 경우는 다른 표준화 환자 가 모니터 혹은 일방향 거울을 보며 채점을 하고 환 자의사관계는 시험방 안에서 연기를 하는 표준화 환자가 채점을 하는 것으로 검토하고 있다고 한다. OSCE 문항의 경우 의과 대학 교수가 채점관이 된 다고 한다. 문항 조합은 일자별로 달라지며 일자별
문항 조합세트의 난이도 차이는 합격선결정위원회 (가칭)에서 검토하여 합격선 결정에 반영될 예정이 다.

\section{3. 의사실기시험 준비 과정에서 보완해야 할 사항}

첫째, 먼저 시험의 공정성을 유지하려면 정보의 공유 효과, 일자별, 문항 조합별, 표준화 환자별 난 이도 차이를 고려해야 할 것이다. 이러한 시험의 공 정성 확보와 합리적인 합격선 결정을 담보하기 위 해서는 실기시험 준비 과정 및 운영에 정신심리측 정전문가 (psychometrician)의 도움이 꼭 필요하다.

둘째, 표준화 환자를 활용한 시험이 믿을 만하고 공정해지기 위해서는 표준화환자의 확보나 훈련이 의과대학과 분리되어 이루어져야 하고 표준화 환자 의 질을 관리하는 구체적인 지침이 마련되어야 한다.

셋째, 채점관의 객관성과 채점의 일관성을 확보하 기 위해 채점관의 훈련이 필요하고, 이에 앞서 객관 성이 높은 채점표와 채점 기준표를 개발해야 한다. 이를 위해서는 문항개발이 단계별로 일정한 수준의 질을 확보해야 한다.

넷째, 정보 공유의 효과를 최소화 하려면 가능한 한 많은 문항을 개발하여 문제 은행식으로 관리 운 영해야 한다. 이렇게 하려면 각 문항의 난이도나 중 요도를 문항 개발 단계에서부터 철저히 검토해야 한다. USMLE의 경우 일년 내내 운영을 해도 정보 공유 효과를 크게 걱정하지 않고 있는 이유는 난이 도나 중요도가 사전에 검증이 된 300 여개 정도 문 항이 문제 은행 안에 들어 있기 때문이라고 한다. 신규 문항의 특성 점검은 USMLE에서는 구체적으 로는 예비 점검 문제 (Ad hoc station) 운영을 통해 이루어진다.

다섯째, 실기시험의 운영에 관한 구체적인 방침이 나 오리엔테이션이 이해 당사자들에게 제대로 이루 어지지 않고 있다. 국시원에서는 적어도 몇 달 후에 시험을 보는 수험생을 위해서라도, 특히 수험생을 교육해야하는 교수를 위해서 시험 운영에 관한 구 체적인 지침과 요점을 수시로 홈페이지나 서면으로 홍보해야 한다.

여섯째, 실기시험의 응시료는 합리적인 선에서 결 
정되어야 하며, 특히 시험의 준비 비용 부담 분산과 시험의 효율적인 운영으로 수험생의 부담을 가능한 한 줄여 주어야 한다.

\section{4. 의사실기시험에 대비한 의과대학 교육의 변화 요구}

사상 초유의 의사실기시험을 준비하는 수험생도 이를 교육해야 하는 교수도 현재로서는 매우 불안 하다. 가장 중요한 이유는 현재 의학 교육에서 임상 실습교육이 실기시험을 언제라도 볼 수 있을 만큼 확실하게 틀이 잡지 않았을 수도 있다는 점이다. 이 에 대한 대처 방안은 교육의 형식을 바꾸는 차원을 넘어서서 학생 교육에서 환자 중심, 문제 해결 중심 의 술기 교육이 실제로 이루어져야 한다.

저학년에서는 모형을 통한 실습교육, 표준화 환자 를 통한 의사소통, 진료 교육이 이루어져야 하고, 임 상 실습 교육에 들어가서는 실제 환자를 대상으로 하는 임상실습교육이 강화 되어야 한다. 사전에 공 지된 의사실기시험 임상 문제 공개항목만을 학습하 는 것이 궁극적인 임상실습의 목표가 되어서는 안 될 것이다. 공개된 수기 문항은 그 문항에 해당하는 술기를 실제로 많이 연습하고 실제 환자에게 학생 들이 직접 적용해 보아야 한다. 진료 문항을 제대로 해결하기 위해서 수험생은 임상 실습 교육에서 환 자를 외래, 입원, 응급실의 상황에서 다양하게 경험 을 해야 하고, 직접 진료에 참여 할 수 있어야 한다. 학생들은 의사소통술, 임상의학 입문, 신체 진찰 수 기 교육, 임상수기 집중 교육 등의 형태로 임상 술 기 원칙에 대한 교육을 임상 실습 전에 미리 받아야
한다. 임상실습 교육과정에는 $\mathrm{OSCE}$ 혹은 $\mathrm{CPX}$ 시 험의 평가가 주기적으로 있어야 하고 각각의 시험 에 대해 개인 피드백이 이루어져야 한다.

마지막으로, 교수의 임상실습 교육에 대한 태도와 열정이 달라져야 한다. 이러한 변화를 유도하기 위 해서는 의학교육이 교수에게 매력적인 업무가 되도 록 유인책이 마련되어야 한다. 구체적인 대안으로는 업적 평가나 교수 인센티브에 의학교육 항목이 추 가 되고 강화되어야 한다. 아울러 임상실습 교육에 대한 다양한 교수 방법이 교수개발과정에 포함되어 야 한다. 한편, 학생들은 기존에 정해진 임상실습 시 간만 관심을 가질게 아니라 실제 환자를 가까이 가 서 보고 배울 수 있는 기회를 병실에서 외래에서 적 극적으로 찾아 나서야 한다. 학생의사가 숨겨진 교 육과정 (hidden curriculum)을 잘 활용할 수 있는 여 건이 되어야 한다. 이를 위해서는 학생의사를 병원 진료의 치료 팀으로 인정해 주고 일정한 역할을 주 어야 한다.

의사 실기시험 하나만으로 의학교육을 쇄신한다 는 것은 자칫 현실과 동떨어진 일방적인 생각일 수 도 있다. 하지만 실기 시험 자체는 적어도 의과 대 학 학생은 무엇을 언제 어떻게 배워야 하고, 교수는 무엇을 어떻게 얼마큼 가르쳐야 하는가에 대한 지 침이 될 수는 있다. 따라서 시험 운영기관에서는 시 험의 신뢰도와 공정성을 유지하는 노력도 있어야 하지만 시험의 파급효과도 고려해서 시험의 목표 설정이나 시험 운영에 있어 지속적으로 의과대학, 한국의과대학 - 의학전문대학원장협회, 관련 학회의 의견을 반영하는 노력이 있어야 할 것이다. 